\title{
Alcohol consumption and employment: a cross-sectional study of office workers and unemployed people
}

\author{
Simone De Sio ${ }^{\text {Corresp., } 1}$, Roberta Tittarelli ${ }^{2}$, Giuseppe Di Martino ${ }^{3}$, Giuseppe Buomprisco ${ }^{4}$, Roberto Perri ${ }^{4}$, \\ Guglielmo Bruno $^{4}$, Flaminia Pantano ${ }^{5}$, Giulio Mannocchi ${ }^{6}$, Enrico Marinelli ${ }^{5}$, Fabrizio Cedrone ${ }^{3}$ \\ ${ }^{1}$ School of Occupational Medicine - U.R. Occupational Medicine, "Sapienza" University of Rome, Rome, Italy \\ 2 Unit of Forensic Toxicology, Department of Anatomical, Histological, Forensic and Orthopedic Sciences, "Sapienza" University of Rome, Rome, Italy \\ 3 School of Hygiene and Preventive Medicine, University "G.d'Annunzio" of Chieti-Pescara, Chieti, Italy \\ 4 School of Occupational Medicine - U.R. Occupational Medicine, "Sapienza" University of Rome, Rome, Italy \\ 5 Unit of Forensic Toxicology - Department of Anatomical, Histological, Forensic and Orthopedic Sciences, "Sapienza” University of Rome, Rome, Italy \\ 6 Bioethics and Legal Medicine Centre, School of Law, University of Camerino, Camerino, Italy \\ Corresponding Author: Simone De Sio \\ Email address: simone.desio@uniroma1.it
}

Background Alcohol is a psychoactive substance with toxic and addictive properties. Biomarkers like GGT, AST, ALT and MCV are influenced by excessive ethanol consumption. Alcohol consumption represents a health risk and it has been linked to unemployment. The aim of this study how working status predict alcohol consumption through a cross sectional study comparing alcohol-related biomarkers levels in office workers and unemployed people.

Methods This study includes 157 office workers and 157 unemployed people, who were recruited from January to December 2018. A propensity score matching procedure was applied to obtain two homogenous groups in terms of age and gender. A non-parametric analysis was performed on serum biomarkers that are generally altered by alcohol consumption. Logistic regression models were designed to evaluate how working status predict abnormal biomarker levels related with alcohol consumption.

Results No differences in median biomarker values were found between groups. Logistic regression analysis showed that office work is a negative predictor of pathological biomarker levels. Office workers had a significant relation with the levels of GGT (OR $0.48 ; 95 \% \mathrm{Cl}: 0.28-0.84)$, AST (OR $0.42 ; 95 \% \mathrm{Cl}$ : $0.22-0.78$ ), ALT (OR 0.39; 95\%Cl: 0.23-0.66), and MCV (OR 0.37; 95\%Cl: 0.19-0.70).

Conclusion Office workers had lower absolute frequencies of pathological values of alcohol consumption biomarkers, after matching for age and gender compared with unemployed people. In addition, a significant negative association between office work is a negative predictor of biomarker levels of alcohol consumption. These results showed that work is an important determinant of health and that can represent a benefit for workers in terms of reducing the risk of consuming alcohol. 
1 Alcohol consumption and employment: a cross-

2 sectional study of office workers and unemployed

3 people

Simone De Sio Corresp.,1, Roberta Tittarelli2, Giuseppe Di Martino ${ }^{3}$, Giuseppe Buomprisco ${ }^{4}$, Roberto Perri ${ }^{4}$, Guglielmo Bruno ${ }^{4}$, Flaminia Pantano ${ }^{5}$, Giulio Mannocchi ${ }^{6}$, Enrico Marinelli $^{5}$, Fabrizio Cedrone ${ }^{3}$

${ }^{1}$ School of Occupational Medicine - U.R. Occupational Medicine, "Sapienza" University of Rome, Rome, Italy

2 Unit of Forensic Toxicology, Department of Anatomical, Histological, Forensic and Orthopedic Sciences, "Sapienza" University of Rome, Rome, Italy

3 School of Hygiene and Preventive Medicine, University "G.d'Annunzio" of ChietiPescara, Chieti, Italy

${ }^{4}$ School of Occupational Medicine - U.R. Occupational Medicine, "Sapienza" University of Rome, Rome, Italy

5 Unit of Forensic Toxicology - Department of Anatomical, Histological, Forensic and Orthopedic Sciences, "Sapienza" University of Rome, Rome, Italy

${ }^{6}$ Bioethics and Legal Medicine Centre, School of Law, University of Camerino, Camerino, Italy

Corresponding author: Simone De Sio, U.R. Occupational Medicine "Sapienza" University of Rome, Viale Regina Elena 336 - 00161 Rome, Italy. Email address: simone.desio@uniroma1.it 
39

40

41

42

43

44

45

46

47

48

49

50

51

52

53

54

55

56

57

58

59

60

61

62

63

64

65

66

67

68

69

70

71

72

73

74

75

76

77

78

\section{Abstract \\ Background}

Alcohol is a psychoactive substance with toxic and addictive properties. Biomarkers like GGT, AST, ALT and MCV are influenced by excessive ethanol consumption. Alcohol consumption represents a health risk and it has been linked to unemployment. The aim of this study how working status predict alcohol consumption through a cross sectional study comparing alcohol-related biomarkers levels in office workers and unemployed people.

\section{Methods}

This study includes 157 office workers and 157 unemployed people, who were recruited from January to December 2018. A propensity score matching procedure was applied to obtain two homogenous groups in terms of age and gender. A non-parametric analysis was performed on serum biomarkers that are generally altered by alcohol consumption. Logistic regression models were designed to evaluate how working status predict abnormal biomarker levels related with alcohol consumption.

\section{Results}

No differences in median biomarker values were found between groups. Logistic regression analysis showed that office work is a negative predictor of pathological biomarker levels. Office workers had a significant relation with the levels of GGT (OR 0.48; 95\% Cl: 0.28-0.84), AST (OR 0.42; 95\%Cl: 0.22-0.78), ALT (OR 0.39; 95\% Cl: $0.23-0.66$ ), and MCV (OR 0.37; $95 \% \mathrm{Cl}: 0.19-0.70)$.

\section{Conclusion}

Office workers had lower absolute frequencies of pathological values of alcohol consumption biomarkers, after matching for age and gender compared with unemployed people. In addition, a significant negative association between office work is a negative predictor of biomarker levels of alcohol consumption. These results showed that work is an important determinant of health and that can represent a benefit for workers in terms of reducing the risk of consuming alcohol. 


\section{Introduction}

80 Alcohol is a psychoactive substance with toxic and addictive properties. Its consumption increases the risk for infectious diseases (Taylor et al., 2016; Rehm et al., 2017), noncommunicable diseases (Gao \& Bataller, 2011; Roerecke \& Rehm, 2010; O'Keefe et al., 2014; Klatsky, 2015), and injuries (Seedat et al., 2009; Mitra et al., 2009). Alcohol has direct toxic effects on all organs of the body, including the brain. It is a psychoactive substance which causes addiction and its effects last for hours after consumption (Babor et al., 2010).

The harmful use of alcohol causes 3 million deaths a year, is responsible for $5.1 \%$ of the global disease burden and continues to be one of the main risk factors for illness at a global level. Despite a reduction of drinkers worldwide of about $5 \%$ from $47.6 \%$ to $43.0 \%$ since 2000 , alcohol is still consumed by more than half of the population in three WHO regions, which include the European Region (World Health Organization - WHO, 2018).

Several studies have deepened the knowledge of the relationships between alcohol and work. They highlighted how alcohol reduces employment and increases unemployment, absenteeism and the risk for injuries. Besides, it can also negatively influence productivity and work performance (Mullahy \& Sindelar, 1996; Terza, 2002; MacDonald Z \& Shields, 2004; Johansson et al., 2007; Ames \& Bennet, 2011). This can result in job loss, especially in a competitive job market.

Other studies have shown that the financial challenges associated with unemployment increase tension, anxiety and family discord, and this can lead to an increase in alcohol consumption (Karasek \& Töres, 1990; Peirce et al., 1996; Catalano et al., 2011). In both working and unemployed people, alcohol consumption is often seen as a coping strategy (Merrill \& Thomas, 2013).

Office workers constitute the largest single occupational sector in developed countries (U.S. Bureau of Labor Statistics); the main risk factor they are all exposed to is the visual display terminal (VDT).

Different biomarkers of alcohol consumption are used in clinical practice to evaluate the patient's alcohol use history. Laboratory markers give objective information about alcohol consumption and changes in consumption over time (some of them are sensitive to a recent assumption and others to a long-term use) (Sharpe, 2001). Gamma-glutamyltransferase (GGT) is a transferase that catalyzes the transfer of gamma-glutamyl functional groups. It is present in the cell membranes of many tissues, but is predominantly used as a diagnostic marker for liver disease (Tate \& Meister, 1985). An isolated elevation or disproportionate elevation of GGT compared to other liver enzymes can indicate alcohol abuse or alcoholic liver disease (Kaplan MM, et al., 1985). Despite its poor specificity, $50 \pm 72 \%$ of elevated GGT levels can be explained by excessive alcohol consumption (Kristenson et al., 1980). 
118 Alanine transaminase (ALT) and aspartate transaminase (AST) are transaminase

119 enzyme that catalyze a transamination reaction between an amino acid and an a-keto

120 acid. ALT and AST are found in plasma and in various body tissues but they are most

121 common in the liver. Serum ALT and AST levels and their ratio (AST/ALT ratio) are

122 commonly measured clinically as biomarkers for liver health (Dufour et al., 2000) and

123 alcoholic liver disease (Andresen-Streichert et al., 2018).

124 Mean corpuscular volume (MCV) is a laboratory value that measures the average size

125 and volume of a red blood cell. It has utility in helping determine the etiology of anemia;

126 in particular, megaloblastic anemia can be caused by folate deficiency, which is linked

127 to chronic alcoholism (Maner \& Moosavi, 2020).

128 Carbohydrate deficient transferrin (CDT) is a kind of transferrin (an iron-binding blood

129 plasma glycoprotein that control the level of free iron) that represents less than the $1.6 \%$

130 of the total transferrin found in plasma. As the plasma half-life of CDT is 10-14 days, a

131 raised percentage of CDT is strongly suggestive of chronic excessive alcohol

132 consumption with sensitivity and specificity both approaching $85 \%$. (Bomford \&

133 Sherwood, 2014). In addition, the production of CDT is directly proportional to alcohol

134 intake (Golka \& Wiese, 2004).

135 Biomarkers of alcohol consumption and liver function may respond to even rather low

136 levels of ethanol intake in a gender-dependent manner (Alatalo et al., 2009), the overall

137 accuracy of Carbohydrate-deficient transferrin (CDT) and Gamma-glutamyltransferase

138 (GGT), appear to be the highest in the detection of problem drinking (Anttila et al., 139 2005).

140 It is possible to identify patients with moderate or heavy alcohol consumption: heavy 141 consumption is defined as the ingestion of more than 60 grams of alcohol per day (if 142 protracted for 2 weeks or more, it is considered chronic heavy consumption) (Peterson, 143 2004). Many studies, from the end of the 1980s to today, have analyzed the relationship 144 between unemployment and the use of alcohol (Kerr et al., 1987; Crawford et al., 1987; 145 Forcier, 1988; Lee et al., 1990; Gallant, 1993; Lester, 1996; Popovici \& French, 2013; ) 146 but no one, to date, has evaluated this association considering the biomarkers of 147 alcohol consumption.

148 Considering the recent confirmations of the scientific literature about the usefulness of 149 the laboratory tests mentioned in identifying the use of alcohol (Niemelä et al., 2019), 150 the purpose of this cross-sectional study was to compare serum biomarkers of alcohol consumption among office workers and unemployed people.

152

\section{Materials \& Methods}

Patient selection

This cross-sectional study examined a sample of people who presented for administrative checks (license request, gun license, etc.), from January 2018 to December 2018, to the forensic toxicology laboratory of a large hospital in the city of 
158 Rome. These people were surveyed with one questionnaire, collecting information

159

160

161

162

163

164

165

166

167

168

169

170

171

172

173

174

175

176

177

178

179

180

181

182

183

184

185

186

187

188

189

190

191

192

193

194

195

196

197

about demographic and job characteristics. The subjects who declared to work in offices and to use a video display terminal (VDT) at work for more than 20 hours per week (as defined by current legislation in Italy) were classified as "office workers" (OW); the exposure to VDT has been investigated, because is considered as risky for the health of workers already for a long time (Lim SY et al. 1998). Unemployed people (UP) have been identified as those who declared to be jobless. Housewives and students were considered in the working group as "Others". Finally, OW and UP were included in the study. All participants provided written informed consent for data collection. This research conforms to the principles of the Declaration of Helsinki, in accordance with the "Sapienza" University of Rome's Ethical Commission regulation and with the Italian law; we have communicated to this commission the starting of our observational study (\#02/2018 07/01/2018). We excluded subjects with previous or current liver disease, exposure to hepatotoxic drugs, family history of liver disease, risk factors for viral hepatitis (history of previous transfusions or use of hemoderivates, use of narcotic substances, promiscuous use of syringes, sexual contact with known hepatitis carriers), or exposure to hepatotoxic substances (solvents, paints, pesticides, other).

\section{Sampling methods and biomarkers of alcohol consumption}

Carbohydrate-deficient transferrin (CDT), Gamma-glutamyltransferase (GGT), aspartate aminotransferase (AST), alanine aminotransferase (ALT) levels and mean corpuscular volume (MCV) were measured in all subjects (in the morning, at $8 \mathrm{am}$ ). The analysis of liver biomarkers (GGT, ALT and AST) was performed by enzymatic test (IFCC) with ILAB 650® instrument (Instrumentation Laboratory - Werfen Group, Barcelona, Spain); they were considered to be elevated if higher than the respective standard thresholds: $55 \mathrm{U} / \mathrm{l}, 41 \mathrm{U} / \mathrm{l}, 37 \mathrm{U} / \mathrm{l}$. The analysis of MCV was performed by impedenzometric test with AcT $8 \circledR$ Instrument (Beckman Coulter. Inc, Brea, California, United States) with the range of normal values between $80-100 \mathrm{fL}$. CDT 's analysis was performed with capillary electrophoresis Minicap $®$ (Sebia, Paris, France). The cut-off used for CDT was above $1.6 \%$ as recommended by the assay manufacturer. The levels of carbohydratedeficient transferrin (CDT) are widely used to diagnose alcohol-related disorders in clinical, occupational and forensic contexts (Bortolotti et al, 2018; Heòander et al., 2016) because it is an indicator for long-term alcohol consumption and, after discontinuing drinking, the serum CDT levels usually normalize within approximately 2-4 weeks, but it may take even longer (Jeppsson, Kristensson \& Fimiani, 1993). A shorter halflife has also been described (Neumann \& Spies, 2003). It is well known that a variety of medical conditions may elevate GGT levels as well as several medications (Onigrave et al., 2002). On the contrary, CDT levels are not influenced by common medications or chronic diseases (Arndt, 2001).

Peer) reviewing PDF | (2019:10:41822:2:0:NEW 4 Feb 2020) 
198

199

200

201

202

203

204

205

206

207

208

209

210

211

212

213

214

215

216

217

218

219

220

221

222

223

224

225

226

227

228

229

230

231

232

233

234

235

236

237

\section{Statistical Analysis}

Quantitative variables were summarized as mean and standard deviation (SD) or median interquartile range (IQR) according to their distribution. Shapiro-Wilks test was performed to evaluate normal distribution of continuous variables. Qualitative variables were summarized as frequency and percentage. Due to the differences in the number of enrolled subjects between study groups ( 170 OW vs 270 UP) and in order to remove possible selection bias of our convenience sample, a propensity score matching procedure was performed using a multivariable logistic model with an 8:1 greedy matching algorithm with no replacement (Parsons \& Lori, 2001). All baseline variables included in the matching model are presented in Table 1. The adequacy of covariate balance in the matched sample was assessed via standardized mean differences between two groups, with differences of less than $20 \%$ indicating a good balance (Austin, 2009). Unmatched subjects were discarded from the analysis. Mann-Whitney $U$ test was performed to evaluate differences in the levels of each biomarker between the two groups. Logistic regression models were performed to evaluate if working status (OW vs UP) predicts abnormal levels for each biomarker. We considered as dependent variables the dichotomized values of each biomarker (pathological vs normal) while working status (office workers vs unemployed) was considered as an independent variable. All logistic models were adjusted for propensity score as covariate. The matching procedure was performed in order to remove possible confounders as age and gender that can influence biomarkers' levels. In particular, this is a cross-sectional study and it can be influenced by the selection bias being a convenience sample. Twotailed $p$ values less than 0.05 were considered significant. Statistical analysis was performed using IBM ${ }^{\mathrm{TM}}$ SPSS $^{\circledR}$ Statistics for Windows v23.0 (Armonk, NY: IBM Corp.).

\section{Results}

In the study were enrolled 440 subjects (170 office workers and 270 unemployed), and 242 subjects were excluded. After the propensity score matching procedure, 314 participants were selected, thereof 157 office workers (OW) and 157 unemployed people (UP). Figure 1 shows the steps of the selection procedure. Groups were homogeneous for age and gender, as demonstrated by a standardized mean difference lower than 0.20 (Table 1). The statistical analysis showed that there were no differences in biomarkers levels between the two groups. The differences of median values of CDT, GGT, AST, ALT, and MCV were not statistically significant, as reported in Table 2. Absolute frequencies of abnormal values of any biomarker were always lower among office workers. Logistic regression models showed that OW negatively predict abnormal biomarker levels. Office workers had a significant negative association with the levels of GGT (OR 0.48; 95\%Cl 0.28-0.84), AST (OR 0.42; 95\%Cl 0.22-0.78), ALT (OR 0.39; $95 \% \mathrm{Cl} 0.23-0.66)$, and MCV (OR $0.37 ; 95 \% \mathrm{Cl} 0.19-0.70)$. The results of the logistic regression models were reported in Table 3. 


\section{Discussion}

241

242

243

244

245

246

247

248

249

250

251

252

253

254

255

256

257

258

259

260

261

262

263

264

265

266

267

268

269

270

271

272

273

274

275

276

Work is an important determinant of health and, in the field of occupational medicine, there is often a tendency to emphasize more the risks than the benefits of work.

Especially among people of lower socioeconomic status, unemployment is linked to less healthy lifestyles, higher prevalence of obesity, low consumption of fruits and vegetables and increased consumption of unhealthy foods (Gallus et al., 2013; Dave \& Kelly, 2012). Our results are consistent with the current evidence about the association between unemployment and higher alcohol consumption (Dom et al., 2016). Quite recently, this finding has also been confirmed by a large European study (Bosque-Prous et al., 2015).

Additionally, unemployment increases the risk for binge drinking, as well as death or hospitalization related to alcohol consumption (Popovici \& French, 2013; Czapla et al., 2015). These data are also consistent with other studies conducted outside the EU (Midanik \& Clark, 1995; Cooper, 2011).

The biomarkers considered in this study are widely used in science and forensics to test for alcohol misuse (Andresen-Streichert et al., 2018). In this study, both direct and indirect markers were used. Direct markers are produced when ethanol is metabolized or reacts with the body while indirect markers are enzymes released from dead liver cells following acute or chronic alcohol consumption. The CDT remains in the normal range with a moderate consumption pattern but assumes pathological values with an alcohol intake of more than 50-80 grams of ethanol per day over a period of 1 to 2 weeks (Helander, 2003). An increase in MCV, AST, ALT, and GGT values may indicate hepatic damage because of excessive alcohol consumption (Jastrzębska et al., 2016) and these indirect parameters take a long time to return to baseline. They are very sensitive but less specific than CDT (Andresen-Streichert et al., 2018).

The strength of the study was the propensity score matching procedure that made study groups comparable in terms of baseline characteristics, minimizing possible confounders and the risk of bias in a convenience sample. In addition, the study is based on objective serological data instead of self-reported questionnaires, reducing the risk of bias.

The results of this study must be interpreted considering certain limitations. In fact, we could not match more than one unemployed participant to each office worker, due to the small sample size. In addition, the nature of this study does not allow us to establish a causative relation between alcohol consumption and unemployment or vice-versa. This study also did not consider other possible confounders that might influence the matching procedure.

\section{Conclusions}


277 This study showed that office workers had lower absolute frequencies of pathological

278 values of alcohol consumption biomarkers compared to unemployed people, after

279 matching for age and gender. In addition, office work negatively predicts pathological

280 values of alcohol consumption biomarkers.

281 Office employment seems to be a protective factor against the increase in serum

282 markers of alcohol misuse, compared to unemployed participants.

283 Surely further studies are needed, but our contribution has shown, on the one hand, that

284 the work itself can represent a protective factor against the use of alcohol and, on the

285 other hand, that this relationship can be highlighted through objective variables such as

286 the blood levels of biomarkers of alcohol-induced liver injury.

287

288

289

290

291

292

293

294

295

296

297

298

299

300

301

302

303

304

305

306

307

308

309

310

311

312 
313

314

315

316

317

318

319

320

321

322

323

324

325

326

327

328

329

330

331

332

333

334

335

336

337

338

339

340

341

342

343

344

345

346

347

348

349

350

351

\section{References}

Alatalo P, Koivisto H, Puukka K, Hietala J, Anttila P, Bloigu R, Niemelä O. 2009.

Biomarkers of liver status in heavy drinkers, moderate drinkers and abstainers. Alcohol 44: 199-203.

Ames GM, Bennet JB. 2011. Prevention interventions of alcohol problems in the workplace: A review and guiding framework. Alcohol research \& health 34: 175-87.

Andresen-Streichert, H., Müller, A., Glahn, A., Skopp, G., \& Sterneck, M. 2018. Alcohol biomarkers in clinical and forensic contexts. Deutsches Ärzteblatt International 115: 309.

Anttila P, Järvi K, Latvala J, Romppanen J, Punnonen K, Niemelä O. 2005.

Biomarkers of alcohol consumption in patients classified according to the degree of liver disease severity. Scandinavian Journal of Clinical and Laboratory Investigation 65: 141151.

Arndt T. 2001. Carbohydrate-deficient transferrin as a marker of chronic alcohol abuse: a critical review of pre-analysis, analysis, and interpretation. Clinical Chemistry 47: 1327.

Austin PC. 2009. Balance diagnostics for comparing the distribution of baseline covariates between treatment groups in propensity-score matched samples. Statistics in Medicine 28: 3083-3107.

Babor TF, Caetano R, Casswell S, Edwards G, Giesbrecht N, Graham K, Grube JW, Hill L, Holder H, Homel R, Livingstone M, Osterberg E, Rehem J, Room R, Rossow I. 2010. Alcohol: no ordinary commodity: research and public policy. Oxford University Press. New York (NY)

Bomford A., Sherwood R.A., 2014. Acute and chronic liver disease, Editor(s): William J. Marshall, Marta Lapsley, Andrew P. Day, Ruth M. Ayling, Clinical Biochemistry: Metabolic and Clinical Aspects (Third Edition), Churchill Livingstone, 14: 250-272.

Bortolotti F, Sorio D, Bertaso A, Tagliaro F. 2018. Analytical and diagnostic aspects of carbohydrate deficient transferrin (CDT): a critical review over years 2007-2017. Journal of Pharmaceutical and Biomedical Analysis 147: 2-12. 
352 Bosque-Prous M, Espelt A, Sordo L, Guitart AM, Brugal MT, Bravo MJ. 2015. Job 353 Loss, Unemployment and the incidence of hazardous drinking during the late 2000s

354 355

356

357

358

359

360

361

362

363

364

365

366

367

368

369

370

371

372

373

374

375

376

377

378

379

380

381

382

383

384

385

386

387

388

389

390

391

recession in Europe among adults aged 50-64 Years. PLoS ONE 10: e0140017.

Catalano RA, Goldman-Mellor SJ, Saxton K, Margerison-Zilko CE, Subbaraman M, LeWinn K, Anderson E. 2011. The Health Effects of Economic Decline. Annual Review of Public Health 32: 431-450.

Cooper B. 2011. Economic recession and mental health: An overview. Neuropsychiatry. 25: 113-117.

Crawford A, Plant MA, Kreitman N, Latcham RW. 1987. Unemployment and drinking behaviour: some data from a general population survey of alcohol use. British Journal of Addiction 82: 1007-1016.

Czapla M, Simon JJ, Friederich HC, Herpertz SC, Zimmermann P, Loeber S. 2015. Is binge drinking in young adults associated with an alcohol-specific impairment of response inhibition? European Addiction Research 21: 105-113.

Dave DM, Kelly IR. 2012. How does the business cycle affect eating habits? Social Science \& Medicine 74: 254-262.

Dom G, Samochowiec J, Evans-Lacko S, Wahlbeck K, Van Hal G, McDaid D. 2016. The impact of the 2008 economic crisis on substance use patterns in the countries of the European Union. International Journal of Environmental Research 13: 122.

Dufour DR, Lott JA, Nolte FS, Gretch DR, Koff RS, Seeff LB, 2000. Diagnosis and monitoring of hepatic injury. I. Performance characteristics of laboratory tests. Clin Chem; 46: 2027-2049.

Forcier MW. 1988. Unemployment and alcohol abuse: a review. Journal of Occupational and Environmental Medicine 30: 246-251.

Gallant DM. 1993. Unemployment and alcohol consumption. Alcoholism: Clinical and Experimental Research 17: 722-723.

Gallus S, Odone A, Lugo A, Bosetti C, Colombo P, Zuccaro P, La Vecchia C. 2010. Overweight and obesity prevalence and determinants in Italy: an update to 2010. European Journal of Nutrition 52: 677-85. 
392 Gao B, Bataller R. 2011. Alcoholic liver disease: pathogenesis and new therapeutic

393

394

395

396

397

398

399

400

401

402

403

404

405

406

407

408

409

410

411

412

413

414

415

416

417

418

419

420

421

422

423

424

425

426

427

428

429

430

targets. Gastroenterology 141: 1572-1585.

Golka K, Wiese A., 2004. Carbohydrate-deficient transferrin (CDT)--a biomarker for long-term alcohol consumption. J Toxicol Environ Health B Crit Rev.; 7: 319-337.

\section{Helander A, Wielders J, Anton R, Arndt T, Bianchi V, Deenmamode J, Jeppsson} JO, Whitfield JB, Weykamp C, Schellenberg F.2016. Standardisation and use of the alcohol biomarker carbohydrate-deficient transferrin (CDT). Clinica Chimica Acta 459: 19-24.

Helander A. 2003. Biological markers in alcoholism. Journal of Neural Transmission. Supplementa 66: 15-32.

Jastrzębska I, Zwolak A, Szczyrek M, Wawryniuk A, Skrzydło-Radomańska B, Daniluk J. 2016. Biomarkers of alcohol misuse: recent advances and future prospects. Przegląd Gastroenterologiczny 11: 78-89.

Jeppsson JO, Kristensson H, Fimiani C. 1993. Carbohydrate-deficient transferrin quantified by HPLC to determine heavy consumption of alcohol. Clinical Chemistry 39: 2115-2120.

Johansson E, Alho H, Kiiskinen U, Poikolainen K. 2007. The association of alcohol dependency with employment probability: Evidence from the population survey 'Health 2000 in Finland.'. Health Economics 16: 739-754.

Kaplan MM. 1985. Biochemical basis for serum enzyme abnormalities in alcoholic liver disease. In Chang NC, Chan NM (eds.). Early identification of alcohol abuse. Research Monograph No. 17. NIAAA. p. 186.

Karasek RA, Töres T. 1990. Healthy Work: Stress, Productivity, and the reconstruction of Working Life. Basic Books. New York, p. 400.

Kerr MH, Campbell FC, Rutherford WH. 1987. Unemployment, alcohol and injury in west Belfast. Injury 18: 313-314.

Klatsky A. 2015. Alcohol and cardiovascular diseases: where do we stand today? Journal of Internal Medicine 278: 238-250. 
431 Kristenson H, Trell E, Fex G, Hood B, 1980. Serum gamma-glutamyltransferase:

432 statistical distribution in a middle-aged male population and evaluation of alcohol habits 433 in individuals with elevated levels. Prev Med. 9: 108-119.

434

435

436

437

438

439

440

441

442

443

444

445

446

447

448

449

450

451

452

453

454

455

456

457

458

459

460

461

462

463

464

465

466

467

468

Lee AJ, Crombie IK, Smith WC, Tunstall-Pedoe H. 1990. Alcohol consumption and unemployment among men: the Scottish Heart Health Study. British Journal of Addiction 85: 1165-1170.

Lester D. 1996. Unemployment and alcohol consumption. Psychological Reports 79: 150.

Lim S., Sauter S.L., Schnorr T.M. 1998. Occupational and Health Aspects of Work with Video Display Terminals, In Rom W.N., Environmental and Occupational Medicine. Third Edition. Lippincott-Raven Pub. Philadelphia, pp. 1333-1344.

MacDonald Z, Shields M. 2004. Does problem drinking affect employment? Evidence from England. Health Economics 13: 139-155.

Maner BS, Moosavi L. 2020. Mean Corpuscular Volume (MCV). In: StatPearls.

Treasure Island (FL): StatPearls Publishing.

Merrill, JE, Thomas SE. 2013. Interactions between adaptive coping and drinking to cope in predicting naturalistic drinking and drinking following a lab-based psychosocial stressor. Addictive Behaviors 38: 1672-1678.

Midanik LT, Clark WB. 1995. Drinking-related problems in the United States:

Description and trends, 1984-1990. Journal of Studies on Alcohol and Drugs 56: 395402.

Mitra B, Charters KE, Spencer JC, Fitzgerald MC, Cameron, PA. 2017. Alcohol intoxication in non-motorized road trauma. Emergency Medicine Australasia 29: 96100.

Mullahy J, Sindelar JL. 1996. Employment, unemployment, and problem drinking. Journal of Health Economics 15: 409-34.

Neumann T, Spies C. 2003. Use of biomarkers for alcohol use disorders in clinical practice. Addiction 98: 81-91. 
469 Niemelä O, Nivukoski U, Bloigu A, Bloigu R, Aalto M, Laatikainen T, 2019.

470 Laboratory test based assessment of WHO alcohol risk drinking levels. Scand J Clin

471 Lab Invest. 79: 58-64.

472

473

O'Keefe JH, Bhatti SK, Bajwa A, Dinicolantonio JJ, Lavie CJ. 2014. Alcohol and

474 cardiovascular health: the dose makes the poison... or the remedy. Mayo Clinic

475 Proceedings 89: 382-393.

476

477

Onigrave KM, Degenhardt LJ, Whitfield JB, Saunders JB, Helander A, Tabakoff B.

478 2002. CDT, GGT, and AST as markers of alcohol use: the WHO/ISBRA collaborative

479

480

481

482

483

484

485 project. Alcoholism: Clinical and Experimental Research 26: 332-339.

Parsons Lori S. 2001. "Reducing Bias in a Propensity Score Matched-Pair Sample Using Greedy Matching Techniques.".

Peirce RS, Frone MR, Marcia R, Cooper ML. 1994. Relationship of financial strain and psychosocial resources to alcohol use and abuse: The mediating role of negative affect

486

487

488 and drinking motives. Journal of Health and Social Behavior 35: 291-308.

489

Peterson K. 2004. Biomarker for alcohol use and abuse - A summary. Alcohol research \& health 28: $30-37$

490

491

Popovici I, French MT. 2013. Binge drinking and sleep problems among young adults.

492 Drug and Alcohol Dependence 132: 207-15.

493

Rehm J, Gmel GE, Gmel G, Hasan OS, Imtiaz S, Popova S, Probst C, Roecrecke M, Room R, Samokhvalov AV, Shield KD, Shuper PA. 2017. The relationship between different dimensions of alcohol use and the burden of disease - an update. Addiction 497 498 112: 968-1001.

500

Roerecke M, Rehm J. 2010. The cardioprotective association of average alcohol 501 consumption and ischaemic heart disease: a systematic review and meta-analysis. Addiction 107: 1246-60.

502

Seedat M, Van Niekerk A, Jewkes R, Suffla S, Ratele K. 2009. Violence and injuries

504 in South Africa: prioritising an agenda for prevention. The Lancet 374: 1011-1022.

505

506

Sharpe PC, 2001. Biochemical detection and monitoring of alcohol abuse and

507 abstinence. Ann Clin Biochem. 38: 652-664. 
509 Tate SS, Meister A 1985. Gamma-Glutamyl transpeptidase from kidney. Methods

510 Enzymol. 113: 400-419.

511

512 Taylor A, Denniston M, Klevens R, McKnight-Eily L, Jiles R. 2016. Association of

513 hepatitis $C$ virus with alcohol use among U.S. adults: NHANES 2003-2010. American

514 Journal of Preventive Medicine 51: 206-215.

515

516 Terza JV. 2002. Alcohol abuse and employment: A second look. Journal of Applied

517 Economics 17: 393-404.

518

519 United States Department of Labor. Employment Project program., U.S. Bureau of 520 Labor Statistics; Available from: http://www.bls.gov/emp/ep_table_101.htm.

521

522 World Health Organization. Global status report on alcohol and health 2018.

523 Accessed at: https://apps.who.int/iris/bitstream/handle/10665/274603/9789241565639-

524 eng.pdf

525

526 


\section{Figure 1}

Figure 1

This figure shows the steps of the selection procedure.

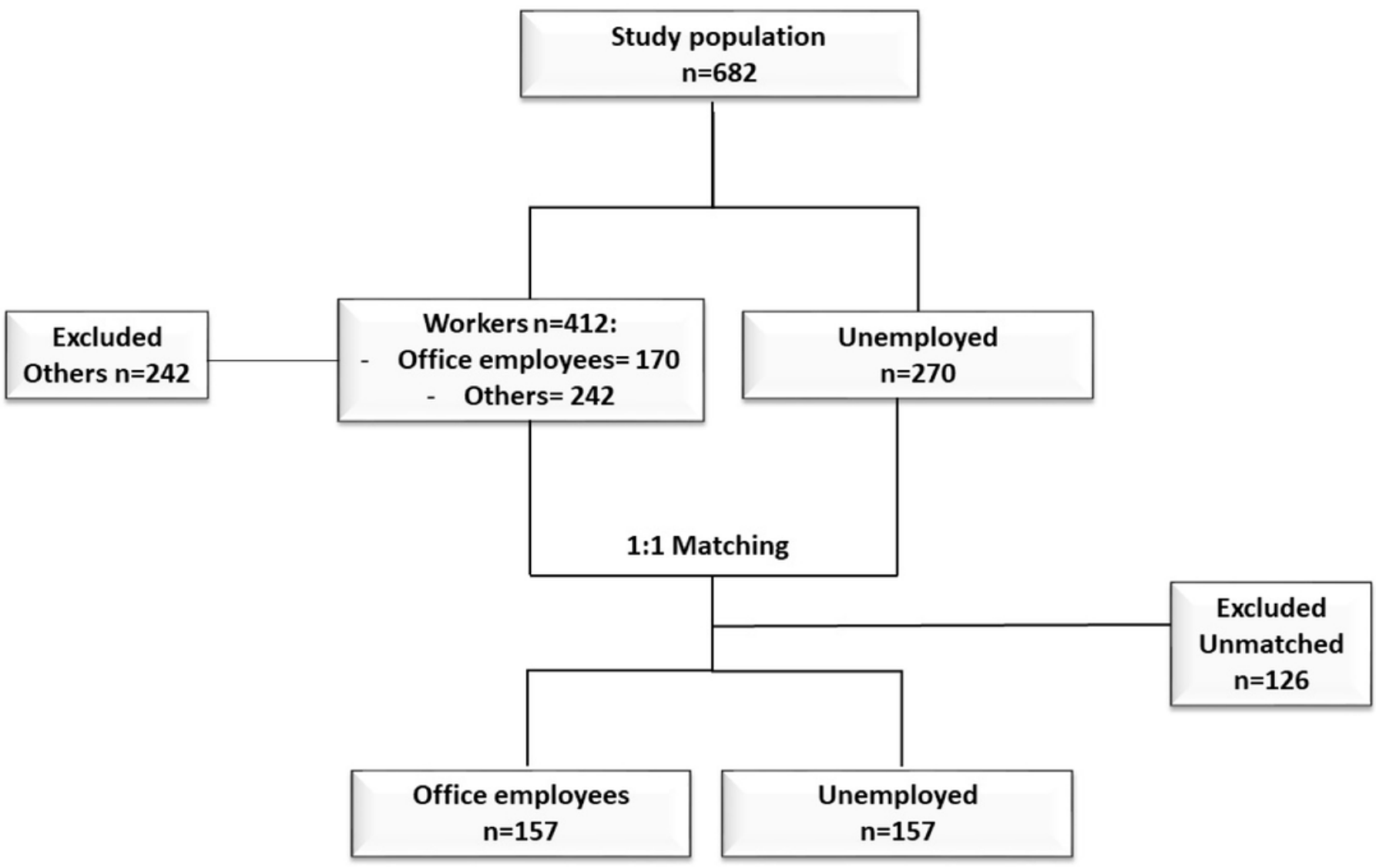




\section{Table $\mathbf{1}$ (on next page)}

Patients' baseline characteristic before and after the matching procedure 
1 Table 1. Patients' baseline characteristic before and after the matching procedure.

\begin{tabular}{|c|c|c|c|c|c|}
\hline & \multicolumn{2}{|c|}{ Unmatched } & \multicolumn{2}{|l|}{ Matched } & \multirow{2}{*}{$\begin{array}{l}\text { Standardize } \\
\text { d mean } \\
\text { difference }\end{array}$} \\
\hline & $\begin{array}{l}\text { Office } \\
\text { Workers } \\
(n=170)\end{array}$ & $\begin{array}{l}\text { Unemployed } \\
\text { People } \\
(n=270)\end{array}$ & $\begin{array}{l}\text { Office } \\
\text { Workers } \\
(n=157)\end{array}$ & $\begin{array}{l}\text { Unemployed } \\
\text { People } \\
(n=157)\end{array}$ & \\
\hline & n (\%) & n (\%) & n (\%) & $\mathrm{n}(\%)$ & \\
\hline $\begin{array}{l}\text { Age mean } \\
\text { (SD) }\end{array}$ & $38.3(10.0)$ & $35.7(13.8)$ & $\begin{array}{l}38.3 \\
(10.4)\end{array}$ & $38.9(12.4)$ & -0.05 \\
\hline $\begin{array}{l}\text { Males } \\
(\%)\end{array}$ & $145(85.2)$ & $217(80.3)$ & $133(84.7)$ & $124(79.0)$ & -0.16 \\
\hline $\begin{array}{l}\text { Females } \mathrm{n} \\
(\%)\end{array}$ & 25 (14.7) & 53 (19.6) & 24 (15.3) & $33(21.0)$ & 0.16 \\
\hline $\begin{array}{l}\text { Propensity } \\
\text { score }\end{array}$ & 0.403 & 0.390 & 0.402 & 0.398 & 0.07 \\
\hline
\end{tabular}

2 


\section{Table 2 (on next page)}

Differences in biomarker values between office workers and unemployed in matched and unmatched populations. 
1 Table 2. Differences in biomarker values between office workers and unemployed in matched and unmatched populations.

\begin{tabular}{|c|c|c|c|c|c|c|}
\hline & \multicolumn{2}{|c|}{ Unmatched $(n=582)$} & \multirow[b]{2}{*}{$p$-value ${ }^{*}$} & \multicolumn{2}{|c|}{ Matched $(n=314)$} & \multirow[b]{2}{*}{$p$-value* } \\
\hline & $\begin{array}{l}\text { Office Workers } \\
(n=170) \\
\text { Median (IQR) }\end{array}$ & $\begin{array}{l}\text { Unemployed } \\
(n=270) \\
\text { Median (IQR) }\end{array}$ & & $\begin{array}{l}\text { Office Workers } \\
(n=157) \\
\text { Median (IQR) }\end{array}$ & $\begin{array}{l}\text { Unemployed } \\
(n=157) \\
\text { Median (IQR) }\end{array}$ & \\
\hline CDT \% & $0.7(0.6-0.8)$ & $0.7(0.6-0.9)$ & 0.736 & $0.7(0.5-0.8)$ & $0.7(0.6-0.8)$ & 0.350 \\
\hline AST U/L & $\begin{array}{l}19.5(17.0- \\
22.0)\end{array}$ & $\begin{array}{l}19.0(17.0- \\
23.0)\end{array}$ & 0.970 & $\begin{array}{l}20.5(17.0- \\
25.0)\end{array}$ & $\begin{array}{l}20.0(17.0- \\
23.0)\end{array}$ & 0.211 \\
\hline ALT U/L & $\begin{array}{l}20.0(16.0- \\
27.0)\end{array}$ & $\begin{array}{l}19.0(15.0- \\
26.0)\end{array}$ & 0.536 & $\begin{array}{l}19.0(14.0- \\
30.8)\end{array}$ & $\begin{array}{l}20.0(16.0- \\
26.0)\end{array}$ & 0.953 \\
\hline GGT U/L & $\begin{array}{l}20.5(15.0- \\
29.0)\end{array}$ & $\begin{array}{l}20.0(14.0- \\
31.0)\end{array}$ & 0.517 & $\begin{array}{l}21.0(15.0- \\
32.5)\end{array}$ & $\begin{array}{l}20.0(15.0- \\
29.0)\end{array}$ & 0.860 \\
\hline $\mathrm{MCV} \mathrm{fl}$ & $\begin{array}{l}91.6(89.8- \\
94.8)\end{array}$ & $\begin{array}{l}92.6(89.7- \\
94.9)\end{array}$ & 0.243 & $\begin{array}{l}93.1(90.0- \\
95.6)\end{array}$ & $\begin{array}{l}91.6(89.9- \\
94.8)\end{array}$ & 0.278 \\
\hline
\end{tabular}

2 


\section{Table 3(on next page)}

Logistic regression models evaluating the association between pathological of studied parameters values and office workers 
1 Table 3. Logistic regression models evaluating the association between pathological of

2 studied parameters values and office workers

\begin{tabular}{|l|l|l|l|l|l|}
\hline & $\begin{array}{l}\text { Office workers } \\
(\mathrm{n}=157) \\
\mathrm{n}(\%)\end{array}$ & $\begin{array}{l}\text { Unemployed } \\
(\mathrm{n}=157) \\
\mathrm{n}(\%)\end{array}$ & Odd Ratio* & $95 \% \mathrm{Cl}$ & $p$-value \\
\hline CDT & $11(7.0)$ & $21(13.4)$ & 0.47 & $0.22-1.03$ & 0.060 \\
\hline AST & $19(12.1)$ & $37(23.6)$ & 0.42 & $0.22-0.78$ & 0.006 \\
\hline ALT & $30(34.8)$ & $127(55.7)$ & 0.39 & $0.23-0.66$ & 0.001 \\
\hline GGT & $28(17.8)$ & $46(29.3)$ & 0.48 & $0.28-0.84$ & 0.011 \\
\hline MCV & $17(10.8)$ & $37(23.6)$ & 0.37 & $0.19-0.70$ & 0.002 \\
\hline
\end{tabular}

${ }^{*}$ All models were adjusted for propensity score; Unemployed People were selected as reference 